Corresponding Author:

Fatima Abd Alraheem Osman; email: FatimaAbdelraheem93@gmail.com

Received 2 March 2019

Accepted 4 April 2019

Published 28 June 2019

Production and Hosting by

Knowledge E

(c) Fatima Abd Alraheem Osman et al. This article is distributed under the terms of the Creative Commons

Attribution License, which permits unrestricted use and redistribution provided that the original author and source are credited.

Editor-in-Chief:

Prof. Mohammad A. M. Ibnouf

\title{
Non-adherence to Antihypertensive Medication and Its Associated Factors Among Cardiac Patients at Alshaab Referred Clinic, November 2017
}

\author{
Fatima Abd Alraheem Osman", Huda Hassan Mohamed ${ }^{2,3}$, and \\ Nazik Ahmed Alhaj ${ }^{4}$ \\ ${ }^{1}$ Faculty of Medicine, University of Khartoum, Khartoum, Sudan \\ ${ }^{2}$ Department of Community Medicine, University of Khartoum, Sudan \\ ${ }^{3}$ Faculty of Public Health, Andrews Place, London, UK \\ ${ }^{4}$ Alshaab Teaching hospital, Khartoum, Sudan
}

\section{Abstract}

Background: Non-adherence to antihypertensive drugs is identified to have negative impact on cardiovascular outcome. Various studies have been conducted on this issue worldwide but data about medications adherence and its associated factors in Sudan are limited.

Objectives: The objectives of this study are to identify the prevalence and factors associated with non-adherence to antihypertensive medications among cardiac patients in Sudan.

Methods: A descriptive cross-sectional study was conducted on 202 patients by total coverage of all diagnosed hypertensive patients with cardiac disease who attended the referred clinic at Alshaab teaching hospital during the study period from November 5th to December 7th, 2017.

Data were collected by direct interview of the patients using structured questionnaire, clinical characteristics of the patients were obtained from the medical records, WISEWOMAN medications adherence questionnaire for hypertension was used to assess the level of medication adherence. Descriptive and multivariate logistic regression was used for data analysis, using SPSS version 20.

Results: Out of 202 participants, 140 (69.3\%) were female, the mean age of the participants was $60.74 \pm 13.6$. The study revealed that $41.6 \%$ of the patients were nonadherent to their antihypertensive medications, the level of non-adherence was found to be significantly associated with young age ( $p$-value $<0.012)$, high level of education ( $p$-value $<0.05$ ), and using more than one pharmacy to get the medications ( $p$-value $<0.00$ ); after logistic regression analysis, non-adherence was found to be significantly associated with using more than one pharmacy to get the medications ( $p$-value < 0.00). The level of non-adherence in our study is found to be corresponding to the findings of other similar local, regional, and international studies, which have reported that non-adherence of medication ranged between 39.5\% and 55.9\%. Other factors in different studies were found to be significantly associated with non-adherence such as gender, duration of hypertension, duration between follow-up visits to physician and number of drugs.

\section{G OPEN ACCESS}


Conclusion: The study results show high prevalence of non-adherence; this is associated more with using more than one pharmacy to get the medications, young age, and higher level of education. In order to improve the adherence to antihypertensive medications in our country, we recommend the use of medications adherence scale as routine tool in the outpatient clinic to identify the non-adherent patients. Doctors must make sure that the drugs are available in the pharmacies around their area before prescription, and to conduct more studies to identify the barriers to adherence specially in young and educated patients.

Keywords: non-adherence, antihypertensive medications, cardiac patients, associated factors

\section{Introduction}

Hypertension is defined as "a systolic blood pressure equal to or above $140 \mathrm{~mm} \mathrm{Hg}$ and/or diastolic blood pressure equal to or above $90 \mathrm{~mm} \mathrm{Hg"} \mathrm{[19].}$

The practical definition of hypertension is the level of BP at which the benefit of treatment out-weight the cost and hazards [1].

Hypertension have adverse effect on many organs including blood vessels, heart, kidney, CNS, and retina [1]. And it contributes to the premature mortality and disability. The main objective of antihypertensive therapy is to reduce the incidence of cardiovascular complications [1].

Randomized controlled trials have demonstrated that antihypertensive therapy can reduce the incidence of stroke and to lesser extent coronary artery diseases [1].

Options of treatment include:

Non-drug therapy: lifestyle modification

Antihypertensive drugs

The adherence to medications is defined as "the extent to which a patient behavior with respect to taking medications corresponds with agreed recommendations from healthcare provider [2, 5]."

Only $29 \%$ of hypertensive patients in the USA have good control, and overall adherence rate of medication were about 50\% [2]. In the USA, 33.69\% of avoidable cases of hospital admissions were due to poor adherence [2]. 
There is limited published literature about adherence to antihypertensive medications in Sudan, a hospital-based study was conducted during 1997 in Kassala; compliance was measured using the pill count method, and it was found to be about $59.6 \%$.

Many factors contribute to the medication non-adherence, and WHO categorized those factors into five groups including: patients, therapy, conditions, socioeconomic and health-system-related factors [2, 4]. As seen in sub-Saharan Africa countries, there are many social and economic barriers, inequalities in the distribution of services, staff shortage in healthcare facilities, limited supply of medications, and limited capacity to conduct clinical investigations [2]."

This study aims to measure the prevalence of medication non-adherence among hypertensive patients with cardiovascular diseases and identify the factors that are associated with non- adherence.

\section{Methodology}

This study was an observational descriptive hospital-based cross-sectional study that was conducted between November 5 and December 7, 2017, at Al-shaab referred clinic, Khartoum, Sudan. Al-shaab teaching hospital is the largest public cardiac center in Sudan, patients with cardiac or chest diseases from all parts of Sudan are referred to Al-shaab hospital, and they get a monthly follow-up care at the referred clinic after discharge; there are six cardiac clinics in the week.

All diagnosed hypertensive patients with cardiac disease who attend the referred clinic during the study period were included, while patients with cardiac problem not known to be hypertensive were excluded.

Data were collected through direct interview of the patients using structured questionnaire; clinical characteristics of the patients were obtained from the medical records; WISEWOMEN medications adherence questionnaire for hypertension which is adapted from Morisky medication adherence scale was used to assess the level of medication adherence. Five medical students participated in data collection and interviewing the patients.

The data obtained through the questionnaire include: socio-demographic information, duration of hypertension, duration of treatment, classes and doses of antihypertensive medications, co-morbidities, and level of medication adherence.

The dependent variable of this study was the level of adherence to antihypertensive medication and the independent variables were age, gender, level of education, residence, occupation, age at diagnosis, regular follow-up, duration of treatment, number 
of medication classes and doses, health insurance, side effects of the antihypertensive drugs, availability of the medications in pharmacies, and the presence of other chronic illnesses.

The adherence was measured using three items scale from medication adherence questionnaire for hypertension by WISEWOMAN which is adapted from Morisky Medication adherence Scale (Figure 2). The items were: "Do you sometimes forget to take your high blood pressure pills?;” "Do you ever cut back or stop taking your BP medicine?" Taking medication every day can be inconvenient for some people. Do you ever feel hassled about sticking to your blood pressure treatment plan?"; each item had two responses (yes $=1$, no $=0$ ) and the items were summed, patients were considered as adherent to their medications when they have score $<2$ and non-adherent when score $\geq 2$.

Ethical approval was obtained from the University of Khartoum, Faculty of Medicine, Department of Community Medicine, State Ministry of Health, Research Committee at Al-shaab teaching hospital, and the head nurse at the referred clinic, the permission to use the medication adherence scale was obtained from the authors, and verbal consent was taken from the patients.

Data was entered and analyzed using SPSS software version 20, chi-square was used to determine the association between each independent variable and the level of adherence, then multiple logistic regression was used to identify the factors that significantly affected non-adherence to medications, $p$-value of $\leq 0.05$ was considered as statistically significant.

\section{Results}

A sample of 211 patients were selected for the study, 202 of them participated in the study, 9 patients were excluded because some were very ill and could not complete the interview, and others denied that they had hypertension.

Table 1 shows the socio-demographic characteristics of the participants, $69.3 \%$ of the participants were female, $48.5 \%$ were above 60 years of age, and $43.6 \%$ belonged to the age group 41-60 years with mean age 60.7 (SD 13.6) , $67.8 \%$ were married, $63.4 \%$ lived in urban areas, $40.6 \%$ were not educated (illiterate), $60.4 \%$ were unemployed, and 76.7\% had health insurance.

Table 2 shows diseases and treatments-related factors, $69.8 \%$ were above 40 years of age when diagnosed with hypertension, $76.7 \%$ were visiting doctors for regular follow-up and measurement of blood pressure, $43.6 \%$ were using antihypertensive medications 
for $<5$ years, $65.8 \%$ were using only one class of antihypertensive medications, $65.8 \%$ had only one dose of antihypertensive drug per day, $80.2 \%$ did not have side effects from their antihypertensive medications, $61.4 \%$ were using more than one pharmacy to get their medications, and $96.5 \%$ were taking medications for another chronic illnesses.

Regarding the medication adherence scale, the responses of the participants were as follow: $63.9 \%$ reported that they never forget taking their high blood pressure medications, $58.9 \%$ do not ever cut back or stop taking their medications, and $61.4 \%$ do not feel hassled sticking to their medications and treatment plan, as shown in Table 3. A total of 84 participants (41.6\%) out of 202 were found to be non-adherent to their antihypertensive medications (with score $\geq 2$; Figure 1).

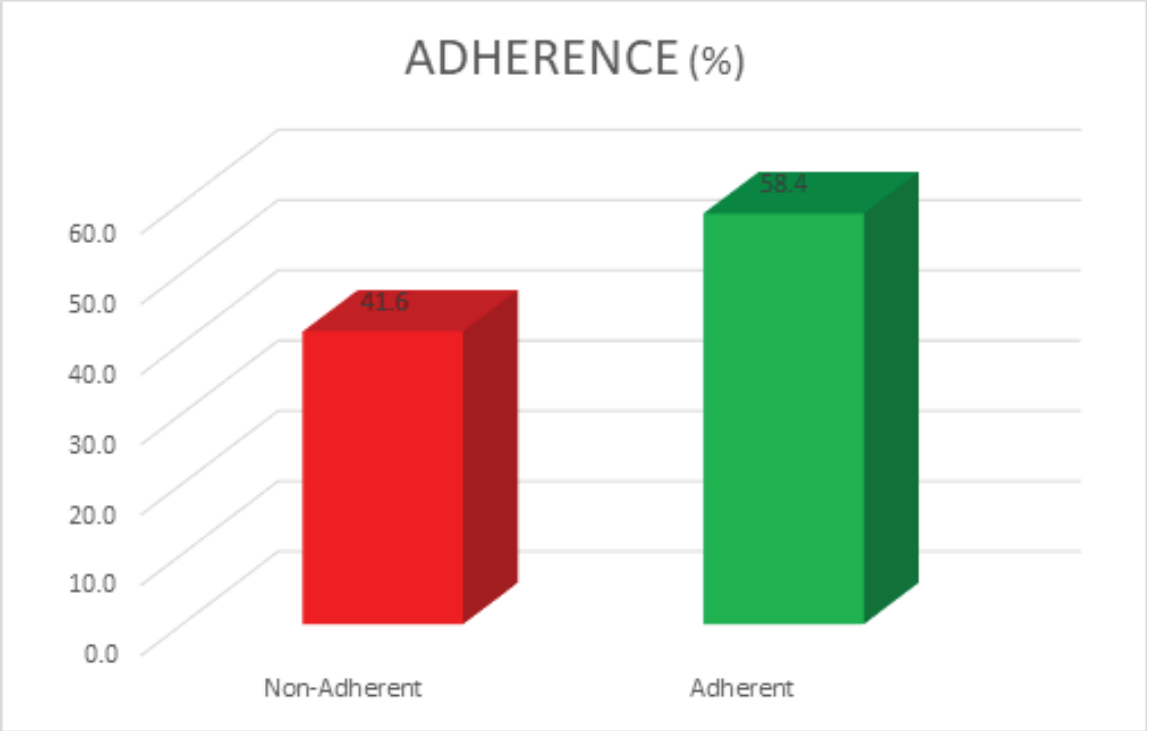

Figure 1: Adherence \%.

Table 4 shows the association between socio-demographic characteristics and the level of adherence to antihypertensive medications, patients who were above 60 years of age were found to be more adherent, illiterate patients also show high level of adherence, other factors including gender, marital status, residence, occupation, and having health insurance don't show significance difference.

Regarding the medications and diseases-related factors and its relation to the level of adherence, those who use more than one pharmacy to get the medications were more non-adherent than those who got their medications from one pharmacy; other factors showed no significant difference (Table 5). 
TABLE 1: Socio-demographic characteristics of the participants.

\begin{tabular}{|c|c|c|}
\hline Characteristic & Number(n) & Frequency(\%) \\
\hline \multicolumn{3}{|l|}{ 1. Age } \\
\hline $20-40$ years & 16 & $7.6 \%$ \\
\hline $41-60$ years & 88 & $43.6 \%$ \\
\hline Above 60 years & 98 & $48.5 \%$ \\
\hline \multicolumn{3}{|l|}{ 2. Gender } \\
\hline Male & 62 & $30.7 \%$ \\
\hline Female & 140 & $69.3 \%$ \\
\hline \multicolumn{3}{|l|}{ 3. Marital status } \\
\hline Single & 6 & $3.0 \%$ \\
\hline Married & 137 & $67.8 \%$ \\
\hline Divorced & 6 & $3.0 \%$ \\
\hline Widow & 53 & $26.2 \%$ \\
\hline \multicolumn{3}{|l|}{ 4. Educational level } \\
\hline Illiterate & 82 & $40.6 \%$ \\
\hline Khalwa & 31 & $15.3 \%$ \\
\hline Primary school & 45 & $22.3 \%$ \\
\hline Secondary school & 34 & $16.8 \%$ \\
\hline University & 8 & $4.0 \%$ \\
\hline Above university & 2 & $1.0 \%$ \\
\hline \multicolumn{3}{|l|}{ 5. Residence } \\
\hline Rural & 74 & $36.6 \%$ \\
\hline Urban & 128 & $63.4 \%$ \\
\hline \multicolumn{3}{|l|}{ 6. Occupation } \\
\hline Unemployed & 122 & $60.4 \%$ \\
\hline Employee & 32 & $15.8 \%$ \\
\hline Trader & 8 & $4.0 \%$ \\
\hline Farmer & 6 & $3.0 \%$ \\
\hline Others & 34 & $16.8 \%$ \\
\hline \multicolumn{3}{|l|}{ 7. Health insurance } \\
\hline Yes & 155 & $76.7 \%$ \\
\hline No & 47 & $23.3 \%$ \\
\hline
\end{tabular}


TABLE 2: Diseases and medications related factors.

\begin{tabular}{|c|c|c|}
\hline Characteristic & Number(n) & Frequency(\%) \\
\hline \multicolumn{3}{|c|}{ 1. The patients age when diagnosed with HTN } \\
\hline$<20$ years & 3 & $1.5 \%$ \\
\hline 20-40 years & 57 & $28.2 \%$ \\
\hline$\geq \mathbf{4 0}$ years & 141 & $69.8 \%$ \\
\hline \multicolumn{3}{|c|}{ 2. Visiting doctors regularly for follow-up } \\
\hline Yes & 155 & $76.7 \%$ \\
\hline No & 47 & $23.3 \%$ \\
\hline \multicolumn{3}{|c|}{ 3. Duration of antihypertensive treatment } \\
\hline$<5$ years & 88 & $43.6 \%$ \\
\hline $5-9$ years & 44 & $21.8 \%$ \\
\hline$\geq 10$ years & 70 & $34.7 \%$ \\
\hline
\end{tabular}

4. Number of antihypertensive classes

One class

Two or more classes

5. Number of doses

Once per day

Twice or more

\begin{tabular}{|c|}
133 \\
69
\end{tabular}

$65.8 \%$

$34.2 \%$

6. Side effects from medications

Yes

39
162
1

$19.3 \%$

No

Missed

\begin{tabular}{|c|} 
macy to get medica \\
124 \\
77 \\
1 \\
\hline
\end{tabular}

$61.4 \%$

Yes

No

Missed

ses

8. Presence of other chronic diseases Yes 195 $96.5 \%$

No 7 $3.5 \%$

9. Types of chronic diseases

Cardiac Diseases

Hyperlipidemia

Diabetes Mellitus

Other comorbidities

\begin{tabular}{|c|}
185 \\
12 \\
64 \\
16 \\
\hline
\end{tabular}

$66.8 \%$

$4.3 \%$

$23.1 \%$

$5.8 \%$ 
Multiple logistic regression analysis revealed that the only variable that has significant effect on non-adherence is using more than one pharmacy to get the medications $(p$ value 0.000 ), other factors were excluded (Table 6).

\section{Discussion}

In this study, we found that about $41.6 \%$ of the participants were non-adherent to their antihypertensive medications, which corresponds to the findings of other similar local, regional, and international studies that have reported medication non-adherence ranging between $39.5 \%$ and $55.9 \%$, despite the difference in the social and economic status of the patients in these countries, and the difference in health system, the prevalence of non-adherence to medications is still high, more studies need to be conducted to identify the barriers to adherence in order to develop the strategies to overcome these barriers $[10,13,15,17,20,21]$

Regarding the socio-demographic factors and its relation to non-adherence, our study revealed that age has significant association with the level of adherence and this contradicts the finding of two other studies that reported that age has no significant effect on non-adherence [15, 17]; regarding the gender, we found that there is no difference between male and female patients in the adherence level, while a study in UAE found that male are more non-adherent than females [15]. Other two studies in Almadina Almunawara and Pakistan found the opposite, which may be due to the difference in the social and cultural beliefs regarding the gender in these areas [14, 16]. In our study, we found that non-adherence is less prevalent among patients with no formal education (illiterate), while a study which was conducted in Finland showed that nonadherence was less prevalent among highly educated patients [7], and these findings may be explained by the difference in the literacy rates between Sudan and Finland; in developed countries, the literacy is about $99.2 \%$, while in sub-Saharan Africa, it is about $64.0 \%$ as reported by UNESCO in 2015; and another study in Saudi Arabia found that highly educated patients were more non-adherent to their medications, other socio-demographic factors including marital status, residence, occupation; having health insurance showed no significant difference and this is in agreement with the two similar studies in the UAE and Iran $[15,17]$.

Diseases- and medications-related factors that include age at diagnosis with hypertension, regular follow-up, duration of treatment, number of medication's classes and doses, side effects of medications, using more than one pharmacy to get the medications and the presence of other comorbidities, all were found to be not significantly 
associated with non-adherence except for using more than one pharmacy to get the medications, which is similar to the findings of a study that is conducted in three cardiac centers in Khartoum and found that one of the major reasons for poor medication adherence among the study participants to be poly-pharmacy; on the other hand, a study conducted in the UAE found that patients who use $\geq$ two medications were more non-adherent than those who use only one drug [15], and another study in Finland showed that patients who experienced side effects of the drugs were significantly more likely to be non-adherent [7].

The literature about medication adherence in Sudan is limited and this makes direct comparison with local studies to be not feasible.

TABLE 3: Responses to medication adherence questionnaire.

\begin{tabular}{|c|c|c|}
\hline Items & Number (n) & Frequency (\%) \\
\hline \multicolumn{3}{|c|}{ 1. Do you sometimes forget to take your high BP medications? } \\
\hline Yes & 71 & $35.1 \%$ \\
\hline No & 129 & $63.9 \%$ \\
\hline Missed & 2 & $1 \%$ \\
\hline \multicolumn{3}{|c|}{ 2. Do you ever cut back or stop taking your medications? } \\
\hline Yes & 83 & $41.1 \%$ \\
\hline No & 119 & $58.9 \%$ \\
\hline \multicolumn{3}{|c|}{ 3. Do you ever feel hassled sticking to your treatment plan? } \\
\hline Yes & 78 & $38.6 \%$ \\
\hline No & 124 & $61.4 \%$ \\
\hline
\end{tabular}

\section{Conclusion}

The study showed that $41.6 \%$ of cardiac patients were non-adherent to their antihypertensive medications, using more than one pharmacy to get the medications was the factor that is significantly associated with non-adherence.

In order to improve the adherence to antihypertensive medications in our country, we recommend the use of medications-adherence scale as routine tool in the out-patient clinic to identify the non-adherent patients. Doctors must make sure that the drugs are available in the pharmacies around their area before prescription and to conduct more studies to identify the barriers to adherence specially in young and literate patients. 
TABLE 4: Association between socio-demographic characteristics and level of adherence to antihypertensive medications.

\begin{tabular}{|c|c|c|c|c|}
\hline The factor & Non-adherence $\mathbf{N} \%$ & Adherence $\mathbf{N} \%$ & $\mathbf{x}^{2}$ & P-value \\
\hline 1. Age & & & 8.796 & 0.012 \\
\hline 20-40 years & $105 \%$ & $63 \%$ & & \\
\hline $41-60$ years & $4321.3 \%$ & $4522.3 \%$ & & \\
\hline Above 60 years & $3115.3 \%$ & $6733.2 \%$ & & \\
\hline 2. Gender & & & 0.304 & 0.0581 \\
\hline Male & $2411.9 \%$ & $3818.8 \%$ & & \\
\hline Female & $6029.7 \%$ & $8039.6 \%$ & & \\
\hline 3. Marital status & & & 0.857 & 0.355 \\
\hline Single & $2411.9 \%$ & $4120.3 \%$ & & \\
\hline Married & $6029.7 \%$ & $7738.1 \%$ & & \\
\hline 4. Educational level & & & 11.05 & 0.050 \\
\hline Illiterate & $2612.9 \%$ & $5627.7 \%$ & & \\
\hline Khalwa & $125.9 \%$ & $199.4 \%$ & & \\
\hline Primary school & $2210.9 \%$ & $2311.4 \%$ & & \\
\hline Secondary school & $2110.4 \%$ & $136.4 \%$ & & \\
\hline University & $21 \%$ & $63 \%$ & & \\
\hline Above university & $10.5 \%$ & $10.5 \%$ & & \\
\hline 5. Residence & & & 0.915 & 0.339 \\
\hline Rural & $3416.8 \%$ & $4019.8 \%$ & & \\
\hline Urban & $5024.8 \%$ & $7838.6 \%$ & & \\
\hline 6. Occupation & & & 1.187 & 0.276 \\
\hline Unemployed & $4723.3 \%$ & $7537.1 \%$ & & \\
\hline Employed & $3718.3 \%$ & $4321.3 \%$ & & \\
\hline 7. Health insurance & & & 1.363 & 0.243 \\
\hline Yes & $6130.2 \%$ & $9446.5 \%$ & & \\
\hline No & $2311.4 \%$ & $2411.9 \%$ & & \\
\hline
\end{tabular}


TABLE 5: The association between medications- and diseases-related factors and the level of adherence.

\begin{tabular}{|c|c|c|c|c|}
\hline The factor & Non-adherence $\mathbf{N} \%$ & Adherence $\mathbf{N} \%$ & $\mathbf{X}^{2}$ & P-value \\
\hline $\begin{array}{l}\text { 1. The patient's age } \\
\text { when diagnosed with } \\
\text { HTN }\end{array}$ & & & 7.469 & 0.058 \\
\hline$<20$ years & $10.5 \%$ & $21 \%$ & & \\
\hline 20-40 years & $3215.8 \%$ & $2512.4 \%$ & & \\
\hline$\geq 40$ years & $5125.2 \%$ & $9044.6 \%$ & & \\
\hline $\begin{array}{l}\text { 2. Visiting doctors } \\
\text { regularly for follow-up }\end{array}$ & & & 0.024 & 0.878 \\
\hline Yes & $6431.7 \%$ & $9145 \%$ & & \\
\hline No & $209.9 \%$ & $2713.4 \%$ & & \\
\hline $\begin{array}{l}\text { 3. Duration of } \\
\text { antihypertensive } \\
\text { treatment }\end{array}$ & & & 1.260 & 0.533 \\
\hline$<5$ years & $3718.3 \%$ & $5125.2 \%$ & & \\
\hline $5-9$ years & $2110.4 \%$ & $2311.4 \%$ & & \\
\hline$\geq 10$ years & $2612.9 \%$ & $4421.8 \%$ & & \\
\hline 4. Number of classes & & & 0.991 & 0.320 \\
\hline One class & $5225.7 \%$ & $8140.1 \%$ & & \\
\hline Two or more classes & $3215.8 \%$ & $3718.7 \%$ & & \\
\hline 5. Number of doses & & & 0.482 & 0.487 \\
\hline Once per day & $5326.2 \%$ & $8039.6 \%$ & & \\
\hline Twice or more & $3115.3 \%$ & $3818.8 \%$ & & \\
\hline $\begin{array}{l}\text { 6. Side effects of } \\
\text { medications }\end{array}$ & & & 1.992 & 0.369 \\
\hline Yes & $146.9 \%$ & $2512.4 \%$ & & \\
\hline No & $6934.2 \%$ & $9346 \%$ & & \\
\hline Missed & $10.5 \%$ & $00.0 \%$ & & \\
\hline $\begin{array}{l}\text { 7. Use more than one } \\
\text { pharmacy to get } \\
\text { medications }\end{array}$ & & & 15.767 & 0.000 \\
\hline Yes & $6532.2 \%$ & $5929.2 \%$ & & \\
\hline No & $199.4 \%$ & $5828.7 \%$ & & \\
\hline Missed & $00.0 \%$ & $10.5 \%$ & & \\
\hline $\begin{array}{l}\text { 8. Presence of another } \\
\text { chronic disease }\end{array}$ & & & 0.723 & 0.395 \\
\hline Yes & $8039.6 \%$ & $11556.9 \%$ & & \\
\hline No & $42 \%$ & $31.5 \%$ & & \\
\hline
\end{tabular}


TABLE 6: Factors associated with non-adherence, logistic regression analysis.

\section{The factor}

1. Using more than one pharmacy to get the medications

\section{Significance}

0.000
$\operatorname{Exp}(B)$

0.183
$95 \% \mathrm{Cl}$

(0.083-0.401)

Date

Adapted from Morisky Medication-Taking Adherence Scale

4/2014

Last Name First Name Middle Initial MBCIS ID (Office Use Only)

1. Do you sometimes forget to take your high blood pressure pills?

$\square$ Yes $\square$ No

1a. If yes, how often?

$\square$ Rarely $\square$ Once in a while $\square$ Sometimes $\square$ Usually $\square$ All the Time

1b. If yes, explain why?

2. Do you ever cut back or stop taking your BP medicine?

$\square$ Yes $\square$ No

If yes, do you cut back or stop taking your BP medicine because you (check all that apply):

2a. $\square$ Feel better?

2b. $\square$ Feel like your blood pressure is under control?

2c. $\square$ Feel worse when you take it?

2d. $\square$ Are having trouble paying for it?

2e. $\square$ Are having trouble getting to the pharmacy?

2f. $\square$ Are not sure why it is important?

3. Are you having any side effects from your medication?

$\square$ Yes $\square$ No

4. Do you use more than one pharmacy to get your medications?

$\square$ Yes $\square$ No

5. Taking medication every day can be inconvenient for some people. Do you ever fee hassled about sticking to your blood pressure treatment plan?

$\square$ Yes $\square$ No

Figure 2: Medication adherence questionnaire for hypertension.

\section{References}

[1] Walker, B., Colledge, N., Ralston, S., (ed.) (n.d.). Davidson's principles and practice medicine. London, UK: Churchill Livingstone.

[2] Okello, S., Nasasira, B., Muiru, A., et al. (2016). Validity and reliability of a self-reported measure of antihypertensive medication adherence in Uganda. PLOS ONE, vol. 11, no. 7, p. e0158499.

[3] Lee, G., Wang, H., Liu, K., et al. (2013). Determinants of medication adherence to antihypertensive medications among a Chinese population using morisky medication adherence scale. PLOS ONE, vol. 8, no. 4, p. e62775. 
[4] Mazzaglia, G., Ambrosioni, E., Alacqua, M., et al. (2009). Adherence to antihypertensive medications and cardiovascular morbidity among newly diagnosed hypertensive patients. Circulation, vol. 120, no. 16, pp. 1598-1605.

[5] Ho, P., Bryson, C., and Rumsfeld, J. (2009). Medication adherence: its importance in cardiovascular outcomes. Circulation, vol. 119, no. 23, pp. 3028-3035.

[6] Monane, M., Bohn, R., Gurwitz, J., et al. (1996). Compliance with antihypertensive therapy among elderly Medicaid enrollees: the roles of age, gender, and race. American Journal of Public Health, vol. 86, no. 12, pp. 1805-1808.

[7] Jokisalo, E., Kumpusalo, E., Enlund, H., et al. (2002). Factors related to noncompliance with antihypertensive drug therapy. Journal of Human Hypertension, vol. 16 , no. 8 , pp. $577-583$.

[8] Bohn, R., Knight, E., Glynn, R., et al. (2002). Noncompliance with antihypertensive medications. Journal of General Internal Medicine, vol. 17, no. 7, pp. 504-511.

[9] Mazzaglia, G., Mantovani, L., Sturkenboom, M., et al. (2005). Patterns of persistence with antihypertensive medications in newly diagnosed hypertensive patients in Italy: a retrospective cohort study in primary care. Journal of Hypertension, vol. 23, no. 11, pp. 2093-2100.

[10] Ruppar, T. (2010). Randomized Pilot study of a behavioral feedback intervention to improve medication adherence in older adults with hypertension. The Journal of Cardiovascular Nursing, vol. 25, no. 6, pp. 470-479.

[11] Lee, H., Jang, S., and Park, E. (2017). Effect of adherence to antihypertensive medication on stroke incidence in patients with hypertension: a population-based retrospective cohort study. BMJ Open, vol. 7, no. 6, p. e014486.

[12] van der Laan, D., Elders, P., Boons, C., et al. (2017). Factors associated with antihypertensive medication non-adherence: a systematic review. Journal of Human Hypertension, vol. 31, no. 11, pp. 687-694.

[13] Osamor, P. and Owumi, B. (2012). Factors associated with treatment compliance in hypertension in southwest Nigeria. Journal of Health, Population and Nutrition, vol. 29 , no. 6 .

[14] Mahmoud, M. (2012). Compliance with treatment of patients with hypertension in Almadinah Almunawwarah: a community-based study. Journal of Taibah University Medical Sciences, vol. 7, no. 2, pp. 92-98.

[15] Bader, R., Koprulu, F., Hassan, N., et al. (2015). Predictors of adherence to antihypertensive medication in northern United Arab Emirates. Eastern Mediterranean Health Journal, vol. 21, no. 5, pp. 309-318. 
[16] Bilal, A., Riaz, M., Shafiq, N., et al. (2015). Non-compliance to antihypertensive medication and its associated factors among hypertensives. Journal of Ayub Medical College Abbottabad, vol. 27, no. 1.

[17] Behnood-Rod, A., Rabbanifar, O., Pourzargar, P., et al. (2016). Adherence to Antihypertensive medications in Iranian patients. International Journal of Hypertension, vol. 2016, pp. 1-7.

[18] Alhaddad, I., Hamoui, O., Hammoudeh, A. et al. (2016). Treatment adherence and quality of life in patients on antihypertensive medications in a Middle Eastern population: adherence. Vascular Health and Risk Management, vol. 12, pp. 407413

[19] WHO. A global brief on hypertension. [online] Retrieved from: http://www.bing.com/c r?IG=2300092FEA6B4D139DB24D095F8FE15D\&CID=3056D227AACE6E07395F D95AAB616FB0\&rd=1\&h=YQeOrJLnX4FTofCmOMIYiz7qGPJMSIOK7qmTXLhopz $Q \& v=1 \& r=$ http\%3a\%2f\%2fwww.who.int\%2fcardiovascular_diseases\%2fpublications \%2fglobal_brief_hypertension\%2fen\%2f\&p=DevEx,5070.1 [Accessed January 20, 2018].

[20] Asgedom, S., Gudina, E., and Desse, T. (2016). Assessment of blood pressure control among hypertensive patients in southwest Ethiopia. PLOS ONE, vol. 11, no. 11, p. e0166432.

[21] Elzubier, A., Husain, A., Suleiman, I., et al. (2000). Drug compliance among hypertensive patients in Kassala, Eastern Sudan. La Revue de sante de la Mediterranee Orientale, vol. 6, no. 1.

[22] Awad, A., Osman, N., and Altayib, S. (2017). Medication adherence among cardiac patients in Khartoum State, Sudan: a cross-sectional study. Cardiovascular Journal of Africa, vol. 28, no. 6, pp. 350-355. 